Case Series

\title{
Pterygopalatine fossa, a hive for fungus in rhino orbital mucormycosis: a case series
}

\author{
Prasanna Darla, Jaya Sandeep Siripalli, Mohanty Deeganta*
} Department of Otorhinolaryngology, Alluri Sitarama Raju Academy of Medical Sciences, Eluru, Andhra Pradesh,
India

Received: 18 December 2021

Revised: 22 January 2022

Accepted: 28 January 2022

\section{*Correspondence:}

Dr. Mohanty Deeganta,

E-mail: deegumohanty@gmail.com

Copyright: (c) the author(s), publisher and licensee Medip Academy. This is an open-access article distributed under the terms of the Creative Commons Attribution Non-Commercial License, which permits unrestricted non-commercial use, distribution, and reproduction in any medium, provided the original work is properly cited.

\begin{abstract}
The study aims to evaluate the involvement of pterygopalatine fossa (PPF) in rhino orbital mucormycosis and to study various outcomes that occurred as a result of the interventions. We conducted a retrospective; observational study performed using $\mathrm{KOH}$ mounts, histopathology, computed tomography paranasal sinuses (CT PNS) scans from June 1 to July 31 in 2021 at Alluri Sitarama Raju academy of medical sciences and hospital, Eluru. A total of 39 cases were admitted during that period. Patients were administered with liposomal amphotericin-B injection, and surgical debridement of local tissues was performed via endoscopic sinus surgery (ESS), modified endoscopic Denker's approach, orbitotomy and maxillectomy. Out of 39 patients, 29 (74.3\%) patients had the involvement of PPF using CT PNS. Most of the patients were male (71.8\%). The $10 \%$ potassium hydroxide $(\mathrm{KOH})$ mounts were found positive in $71.8 \%$. The $94.8 \%$ of patients had a history of COVID-19 infection. ESS via modified Denker's approach was performed in 53.8\%. Our findings show that PPF involvement is the main conduit for the aggressive spread of the rhino orbital mucormycosis disease. Therefore, further treatment with medical and surgical techniques could effectively halt the fatal outcomes of the disease at the earliest stages.
\end{abstract}

Keywords: PPF, Rhino orbital mucormycosis, COVID-19, Liposomal amphotericin-B, Modified Denker's approach, Maxillectomy

\section{INTRODUCTION}

Rhino orbital mucormycosis is a rapidly progressing angioinvasive disease caused by fungi of the genus Mucor, Rhizopus, Rhizomucor of the family Mucoraceae, order Mucorales, and phylum Mucormycota. The prevalence is 0.14 cases per 1000 population, that is 80 times higher in India than the developed countries. ${ }^{1}$ It is predisposed in uncontrolled diabetics, patients receiving steroids, tocilizumab or other immunosuppressants, oxygen therapy or mechanical ventilation, and individuals with hematological malignancies, hematological stem cell transplantations, solid organ malignancies, solid organ transplantations, having iron overload. ${ }^{2}$ The most common risk factor is poorly controlled diabetes in India. ${ }^{3}$ With the irrational use of steroids in COVID-19 in India, many cases were found denovo diabetic leading to a dramatic spike in the number of mucormycosis cases. Depending on its anatomical involvement, the disease is categorized into four stages. In the first stage, nasal cavity mucosa is involved presenting with symptoms like nasal stuffiness, nasal discharge, foul smell and epistaxis. In the second stage, paranasal sinuses are also involved presenting with added symptoms of facial pain, facial edema, dental pain, and systemic symptoms (malaise and fever). In the third stage, orbit is also involved presenting with added symptoms of eye pain, ptosis, proptosis, diplopia, loss of vision, infraorbital and facial $\mathrm{v} 1$, and $\mathrm{v} 2$ nerve anesthesia. In the fourth stage, central nervous system is also 
involved with added symptoms of bilateral proptosis, paralysis, altered consciousness, and focal seizures.

PPF has always been a hive for these cases and is a conduit for extending to the other sites. It is bound anteriorly by the posterior wall of the maxillary sinus, posteriorly by greater wing of sphenoid and pterygoid process, the body of sphenoid and orbital process of palatine bone form the roof, palatine bone forms floor, palatine bone, and nasal mucoperichondrium form the medial wall and temporalis muscle via pterygomaxillary fissure forms the lateral boundary. ${ }^{4}$

The foramen rotundum connects the PPF to middle cranial fossa. The pterygoid canal or the vidian canal, connects the PPF to middle cranial fossa. The palatovaginal canal connects PPF with nasal cavity and nasopharynx. Anteriorly, the inferior orbital fissure connects PPF to orbit. Medially, sphenopalatine foramen provides access to the nasal cavity. Laterally, pterygomaxillary fissure connects PPF to the infratemporal fossa. Inferiorly, the greater palatine canal connects PPF to oral cavity. ${ }^{5}$

The PPF contains multiple vital structures. First and foremost is the pterygopalatine ganglion. Nerve roots from maxillary nerve suspend this ganglion. The second one is the terminal third segment of maxillary artery. Next, the maxillary division of the trigeminal nerve (CN V2) and the vidian nerve (the nerve of the pterygoid canal), which is a combination of the greater petrosal nerve and the deep petrosal nerve, traverse through the PPF as well. ${ }^{4}$ Almost every case has this fossa involved in our case series.

\section{CASE SERIES}

This retrospective study was done from June 12021 to July 312021 in our institution. We were reported with 39 cases.

\section{Inclusion criteria}

Any patients who were having symptoms like nasal obstruction, proptosis, and unilateral cheek pain and suspected to have mucormycosis were included in study.

\section{Exclusion criteria}

All cases having the involvement of the central nervous system in mucormycosis were excluded from this study.

All cases of mucormycosis for whom orbital exenteration was required were also excluded from this study.

These patients were referred to the higher centers for the appropriate treatment.

All the cases were categorized as possible, probable, and proven rhino orbital mucormycosis. In possible cases, patient presents with the typical signs and symptoms. These patients should be kept under observation and managed by supportive treatment. Patients with probable mucormycosis have typical signs and symptoms, as well as supporting evidence found clinically and on the diagnostic nasal endoscopy and/ or contrast-enhanced CT/MRI. This category of patients should be managed with liposomal amphotericin-B and surgical debridement. In proven cases, patients present with features of probable mucormycosis with evidence on direct microscopy/ culture/ histopathology and should be managed with liposomal amphotericin-B and surgical debridement.

All our cases included 11 probable and 28 proven cases of mucormycosis. Liposomal amphotericin-B injection (GILEAD sciences Inc.) was given $5 \mathrm{mg} / \mathrm{kg}$ body weight/day for 14 days preoperatively and postoperatively for five days with strict metabolic control. Each vial of liposomal amphotericin-B contains $50 \mathrm{mg}$. It was diluted in $5 \%$ or $10 \%$ dextrose and is incompatible with normal saline/ Ringer lactate. The above treatment was followed by Posaconazole (POSAONE- MSN Pvt. Ltd.) $300 \mathrm{mg}$ tablet twice on day 1 and continued daily once later on for 8 to 12 weeks.

All the patients were tested for COVID-19 via reverse transcriptase-polymerase chain reaction (RT-PCR) from the nasopharyngeal swab samples at the time of admission. The patients were also asked if they had ever been infected with COVID-19. Biopsy samples from the middle turbinate were sent for $\mathrm{KOH}$ mounts and histopathology. Radiological imaging was done with 1.25 $\mathrm{mm}$ cuts for computed tomography paranasal sinuses for all the patients, and a 1.5-Tesla magnetic resonance imaging (MRI) scan of the orbits and brain with $3 \mathrm{~mm}$ cuts was conducted three days preoperatively for those patients who were suspected of the orbital and intracranial spread. According to the clinical examination, CT, and MRI imaging, surgery was planned. All the case biopsy samples were sent for histopathology postoperatively also. Patients were followed up weekly, once for the first month and biweekly for the second month. The patients were advised postoperatively for saline nasal douching about 7 to 8 times daily. In the follow-up sessions, local application of lipid based amphigel was done in the postoperative wound areas. CT paranasal sinuses were repeated postoperatively after three weeks and checked for complete cure/ any recurrence.

The ethics committee approval was obtained from the institution, (IEC/ASR/APPROVAL/34/2021).

The 37 patients reported positive (94.8\%) for COVID-19 infection in the past, and 2 were not infected (5.2\%). In 39 patients, 29 patients had involvement of PPF, i.e., $(74.3 \%)$ and 10 were controls. The summary of all the 39 patients was compiled and represented in master chart (Table 1). 
Table 1: Representing the master chart of all the patients involved in the study.

\begin{tabular}{|c|c|c|c|c|c|c|c|c|}
\hline Age (Years) & Sex & DM, HTN & COVID-19 history & KOH test & CT scan & Lateral & Stage & $\mathbf{R X}$ \\
\hline 40 & $\mathrm{~F}$ & DM, HTN & Y & $\mathrm{N}$ & Y & $\mathrm{U} / \mathrm{L}$ & 2 & MED \\
\hline 51 & M & DM, HTN & $\mathrm{Y}$ & Y & $\mathrm{Y}$ & $\mathrm{U} / \mathrm{L}$ & 2 & MED \\
\hline 40 & M & DM & $\mathrm{Y}$ & Y & Y & $\mathrm{U} / \mathrm{L}$ & 3 & $\mathrm{MED}+\mathrm{O}$ \\
\hline 47 & M & DM, HTN & $\mathrm{Y}$ & Y & $\mathrm{Y}$ & $\mathrm{U} / \mathrm{L}$ & 2 & MED \\
\hline 55 & $\mathrm{~F}$ & DM & $\mathrm{Y}$ & $\mathrm{Y}$ & $\mathrm{Y}$ & $\mathrm{U} / \mathrm{L}$ & 2 & ESS \\
\hline 50 & M & DM, HTN & $\mathrm{Y}$ & $\mathrm{Y}$ & $\mathrm{Y}$ & $\mathrm{U} / \mathrm{L}$ & 2 & MED \\
\hline 59 & $\mathrm{~F}$ & DM, HTN & $\mathrm{Y}$ & Y & $\mathrm{Y}$ & $\mathrm{U} / \mathrm{L}$ & 2 & ESS+M \\
\hline 58 & M & DM & $\mathrm{Y}$ & $\mathrm{Y}$ & $\mathrm{Y}$ & $\mathrm{U} / \mathrm{L}$ & 3 & $\mathrm{ESS}+\mathrm{M}+\mathrm{O}$ \\
\hline 42 & $\mathrm{~F}$ & DM & $\mathrm{Y}$ & $\mathrm{Y}$ & $\mathrm{Y}$ & $\mathrm{U} / \mathrm{L}$ & 3 & $\mathrm{MED}+\mathrm{O}$ \\
\hline 55 & $\mathrm{~F}$ & HTN & $\mathrm{Y}$ & $\mathrm{Y}$ & $\mathrm{Y}$ & $\mathrm{U} / \mathrm{L}$ & 2 & MED \\
\hline 55 & $\mathrm{~F}$ & DM, HTN & $\mathrm{Y}$ & Y & $\mathrm{Y}$ & $\mathrm{U} / \mathrm{L}$ & 3 & $\mathrm{ESS}+\mathrm{O}$ \\
\hline 30 & M & - & $\mathrm{Y}$ & Y & Y & $\mathrm{U} / \mathrm{L}$ & 2 & ESS \\
\hline 51 & M & DM & $\mathrm{Y}$ & $\mathrm{Y}$ & $\mathrm{Y}$ & $\mathrm{U} / \mathrm{L}$ & 2 & ESS \\
\hline 59 & M & DM, HTN & $\mathrm{Y}$ & $\mathrm{Y}$ & $\mathrm{N}$ & $\mathrm{U} / \mathrm{L}$ & 3 & $\mathrm{MED}+\mathrm{O}$ \\
\hline 36 & M & DM & $\mathrm{Y}$ & $\mathrm{N}$ & $\mathrm{N}$ & $\mathrm{U} / \mathrm{L}$ & 2 & ESS \\
\hline 53 & $\mathrm{~F}$ & - & $\mathrm{Y}$ & $\mathrm{Y}$ & $\mathrm{N}$ & $\mathrm{U} / \mathrm{L}$ & 2 & ESS \\
\hline 57 & M & DM & $\mathrm{Y}$ & $\mathrm{Y}$ & $\mathrm{N}$ & $\mathrm{U} / \mathrm{L}$ & 3 & $\mathrm{ESS}+\mathrm{O}$ \\
\hline 69 & $\mathrm{~F}$ & DM, HTN & $\mathrm{Y}$ & $\mathrm{Y}$ & $\mathrm{N}$ & $\mathrm{U} / \mathrm{L}$ & 2 & ESS \\
\hline 52 & M & $\mathrm{DM}$ & $\mathrm{Y}$ & $\mathrm{N}$ & Y & $\mathrm{U} / \mathrm{L}$ & 2 & MED \\
\hline 58 & M & DM, HTN & Y & $\mathrm{Y}$ & $\mathrm{Y}$ & $\mathrm{U} / \mathrm{L}$ & 2 & MED \\
\hline 57 & M & DM & Y & $\mathrm{Y}$ & $\mathrm{Y}$ & $\mathrm{U} / \mathrm{L}$ & 2 & MED \\
\hline 68 & $\mathrm{~F}$ & DM & Y & $\mathrm{N}$ & $\mathrm{N}$ & $\mathrm{U} / \mathrm{L}$ & 2 & MED \\
\hline 52 & M & DM & $\mathrm{Y}$ & $\mathrm{N}$ & $\mathrm{N}$ & $\mathrm{U} / \mathrm{L}$ & 3 & $\mathrm{MED}+\mathrm{O}$ \\
\hline 55 & M & DM, HTN & $\mathrm{Y}$ & $\mathrm{Y}$ & Y & $\mathrm{U} / \mathrm{L}$ & 2 & MED \\
\hline 54 & M & $\mathrm{DM}$ & Y & $\mathrm{N}$ & $\mathrm{N}$ & $\mathrm{B} / \mathrm{L}$ & 2 & ESS+M \\
\hline 55 & M & DM, HTN & $\mathrm{Y}$ & $\mathrm{Y}$ & $\mathrm{N}$ & $\mathrm{U} / \mathrm{L}$ & 2 & MED \\
\hline 50 & M & DM & $\mathrm{Y}$ & $\mathrm{N}$ & $\mathrm{N}$ & $\mathrm{U} / \mathrm{L}$ & 3 & $\mathrm{MED}+\mathrm{O}$ \\
\hline 69 & $\mathrm{~F}$ & DM, HTN & $\mathrm{Y}$ & $\mathrm{Y}$ & $\mathrm{Y}$ & $\mathrm{U} / \mathrm{L}$ & 3 & MED+O \\
\hline 38 & M & DM & $\mathrm{Y}$ & Y & $\mathrm{N}$ & $\mathrm{U} / \mathrm{L}$ & 2 & ESS+M \\
\hline 47 & M & $\mathrm{DM}$ & $\mathrm{Y}$ & $\mathrm{Y}$ & $\mathrm{Y}$ & $\mathrm{U} / \mathrm{L}$ & 2 & ESS+M \\
\hline 55 & M & DM, HTN & Y & Y & $\mathrm{Y}$ & $\mathrm{U} / \mathrm{L}$ & 3 & $\mathrm{MED}+\mathrm{O}$ \\
\hline 53 & M & - & $\mathrm{Y}$ & $\mathrm{N}$ & $\mathrm{N}$ & $\mathrm{U} / \mathrm{L}$ & 2 & ESS+M \\
\hline 36 & M & DM & $\mathrm{N}$ & $\mathrm{Y}$ & Y & $\mathrm{U} / \mathrm{L}$ & 2 & ESS+M \\
\hline 56 & M & DM & $\mathrm{Y}$ & $\mathrm{N}$ & Y & $\mathrm{U} / \mathrm{L}$ & 2 & ESS+M \\
\hline 70 & M & DM, HTN & $\mathrm{Y}$ & $\mathrm{Y}$ & Y & $\mathrm{U} / \mathrm{L}$ & 2 & ESS+M \\
\hline 41 & M & DM, HTN & $\mathrm{Y}$ & $\mathrm{Y}$ & $\mathrm{Y}$ & $\mathrm{B} / \mathrm{L}$ & 3 & $\mathrm{ESS}+\mathrm{M}+\mathrm{O}$ \\
\hline 36 & M & DM & $\mathrm{N}$ & Y & Y & $\mathrm{U} / \mathrm{L}$ & 2 & MED \\
\hline 56 & $\mathrm{~F}$ & DM, HTN & $\mathrm{Y}$ & $\mathrm{N}$ & $\mathrm{N}$ & $\mathrm{U} / \mathrm{L}$ & 2 & MED \\
\hline 52 & M & DM & $\mathrm{Y}$ & $\mathrm{N}$ & $\mathrm{Y}$ & $\mathrm{U} / \mathrm{L}$ & 2 & MED \\
\hline
\end{tabular}

M-Male, F-Female, DM-Diabetes mellitus, HTN-Hypertension, Y-Yes, N-No, U/L- Unilateral, B/L-Bilateral, Stage 2-involvment of nasal cavity and paranasal sinuses, Stage 3-Involvement of nasal cavity, paranasal sinuses and orbit, RX-Treatment, ESS-Endoscopic sinus surgery, M-Maxillectomy, MED-Modified endoscopic Denker's approach, O-Orbitotomy.

In 39 patients, 28 were males $(71.8 \%)$ and 11 were female $(28.2 \%)$. They ranged in age from $30-70$ years. 7 patients aged 30-40 (17.9\%), 10 patients aged 41-50 (25.6\%), 18 patients aged 51-60 (46.1\%) and 4 patients aged 61-70 (10.2\%) (Table 2).

$\mathrm{KOH}$ mounts were tested for all patients, 28 patients were $\mathrm{KOH}$ positive $(71.8 \%)$, and 11 patients were $\mathrm{KOH}$ negative (28.2\%). 36 patients out of 39 patients were known diabetics, including de novo patients (Table 3).

All 37 patients had unilateral disease except two patients (Table 4).
Debridement was planned for all 39 patients. ESS was performed in 8 patients $(20.5 \%)$, ESS via modified Denker's approach was performed in 21 patients $(53.8 \%)$, and ESS with maxillectomy was performed in 10 patients (25.6\%) (Table 5). Four patients died due to medical complications, and 6 patients had recurrence.

The preoperative CT PNS axial view of a patient in our study shows the mucosal thickening in bilateral maxillary sinuses with bony erosions along the posterolateral and medial walls of the right maxillary sinus with extension into retro maxillary zygomatic area and also soft tissue opacification in PPF area was described in Figure 2 A. 
Table 2: Representing the distribution of patients according to age and gender.

\begin{tabular}{|llllll|}
$\begin{array}{l}\text { Age } \\
\text { (Years) }\end{array}$ & $\mathbf{3 0 - 4 0}$ & $\mathbf{4 1 - 5 0}$ & $\mathbf{5 1 - 6 0}$ & $\mathbf{6 1 - 7 0}$ & $\begin{array}{l}\text { Total } \\
(\%)\end{array}$ \\
\hline Male & 6 & 9 & 12 & 1 & $28(71.8)$ \\
\hline Female & 1 & 1 & 6 & 3 & $11(28.2)$ \\
$\begin{array}{l}\text { Total } \\
(\%)\end{array}$ & 17.9 & 25.64 & 46.15 & 10.25 & $39(100)$ \\
\hline
\end{tabular}

Table 3: Representing the preliminary tests conducted in all the patients.

\begin{tabular}{|lll|}
\hline Type of test & $\begin{array}{l}\text { No. of patients } \\
\text { positive }(\%)\end{array}$ & $\begin{array}{l}\text { No. of patients } \\
\text { negative }(\%)\end{array}$ \\
\hline KOH test & $28(71.8)$ & $11(28.2)$ \\
\hline $\begin{array}{l}\text { CT paranasal } \\
\text { sinuses }\end{array}$ & $29(74.3)$ & $10(25.6)$ \\
\hline Diabetes mellitus & $36(92.3)$ & $3(7.7)$ \\
\hline
\end{tabular}

Table 4: Representing the type of disease involvement in all patients.

\begin{tabular}{|lll|}
\hline $\begin{array}{l}\text { Involvement of } \\
\text { disease }\end{array}$ & Unilateral & Bilateral \\
\hline No. of patients & 37 & 2 \\
\hline
\end{tabular}

Table 5: Representing the type of surgery done.

\begin{tabular}{|c|c|c|c|}
\hline $\begin{array}{l}\text { Type of } \\
\text { surgery }\end{array}$ & ESS (\%) & $\begin{array}{l}\text { ESS via } \\
\text { modified } \\
\text { Denker's } \\
\text { approach }(\%)\end{array}$ & $\begin{array}{l}\text { ESS with } \\
\text { maxillectomy } \\
(\%)\end{array}$ \\
\hline $\begin{array}{l}\text { No. of } \\
\text { patients }\end{array}$ & $8(20.51)$ & $21(53.84)$ & $10(25.64)$ \\
\hline
\end{tabular}

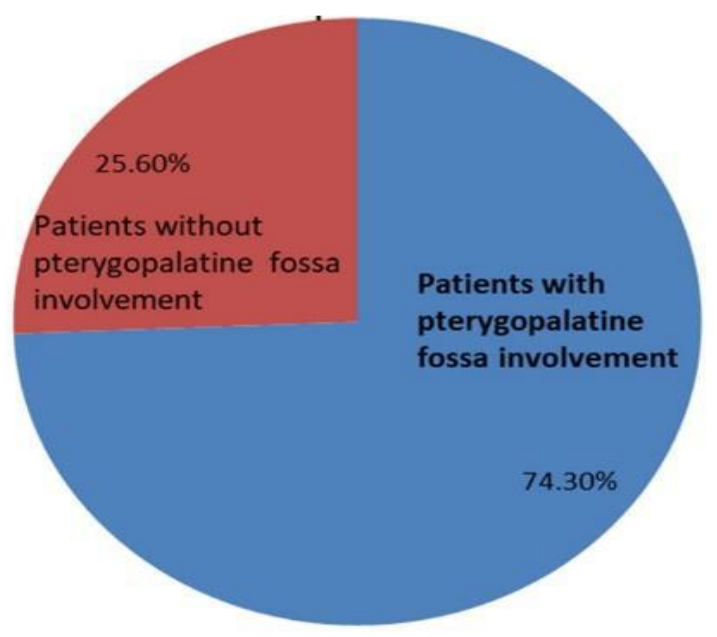

Figure 1: The percentage of patients involving the PPF detected by CT PNS.

The preoperative MRI PNS axial view of one patient in our study-T2 fat-saturated image showing soft tissue with hyperintensity in left PPF, extending into infratemporal fossa via pterygomaxillary fissure was described in
Figure $2 \mathrm{~B}$. There is also the involvement of both medial and lateral pterygoid muscles on the left side. There is complete opacification of the left maxillary sinus seen.

The preoperative image CT PNS coronal view of a patient in our study- showing near total opacification of right maxillary sinus with blockade of osteomeatal complex and bony erosions noted along the posterolateral and medial walls was noted in Figure 2 C. Bony erosions were noted at the hard palate.

The preoperative image CT PNS coronal view of a patient in our study- showing bony erosions at the inferomedial walls of the left orbit, along the hard palate, nasal septum, and turbinates was noted in Figure 2 D.

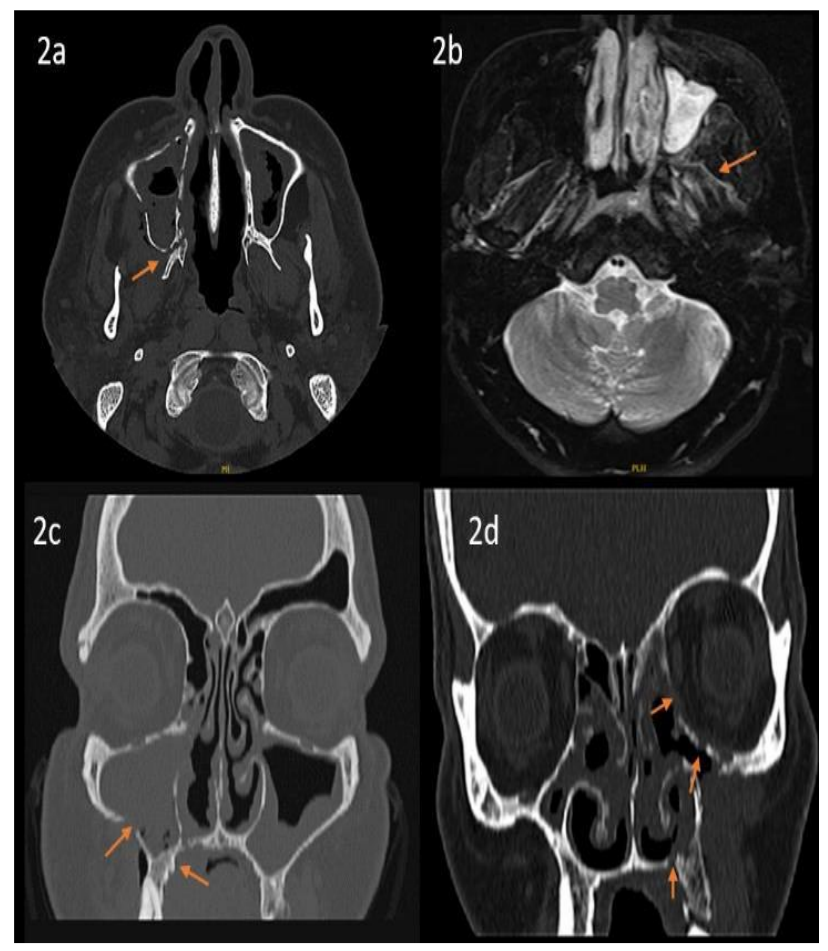

Figure 2 (A-D): (Red arrow) representing CT PNS axial view of a patient with soft tissue density of left PPF area, (red arrows) MRI PNS axial view of a patient showing hyperintensity of left PPF extending into infratemporal fossa, (red arrows) CT PNS coronal view of a patient showing erosions of hard palate and (red arrows) CT PNS coronal view of a patient showing bony erosions at the inferomedial walls of the left orbit.

The intraoperative images of the PPF over the left side, which was reached via modified Denker's approach of ESS, was shown in Figure 3.

The high power (40x magnification scale) histopathological image in Figure 4 shows broad aseptate hyphae with obtuse-angled branching (yellow arrow) and surrounding mixed inflammatory cells composed of neutrophils (red arrow), eosinophils (green arrow), and lymphocytes (black arrow). 


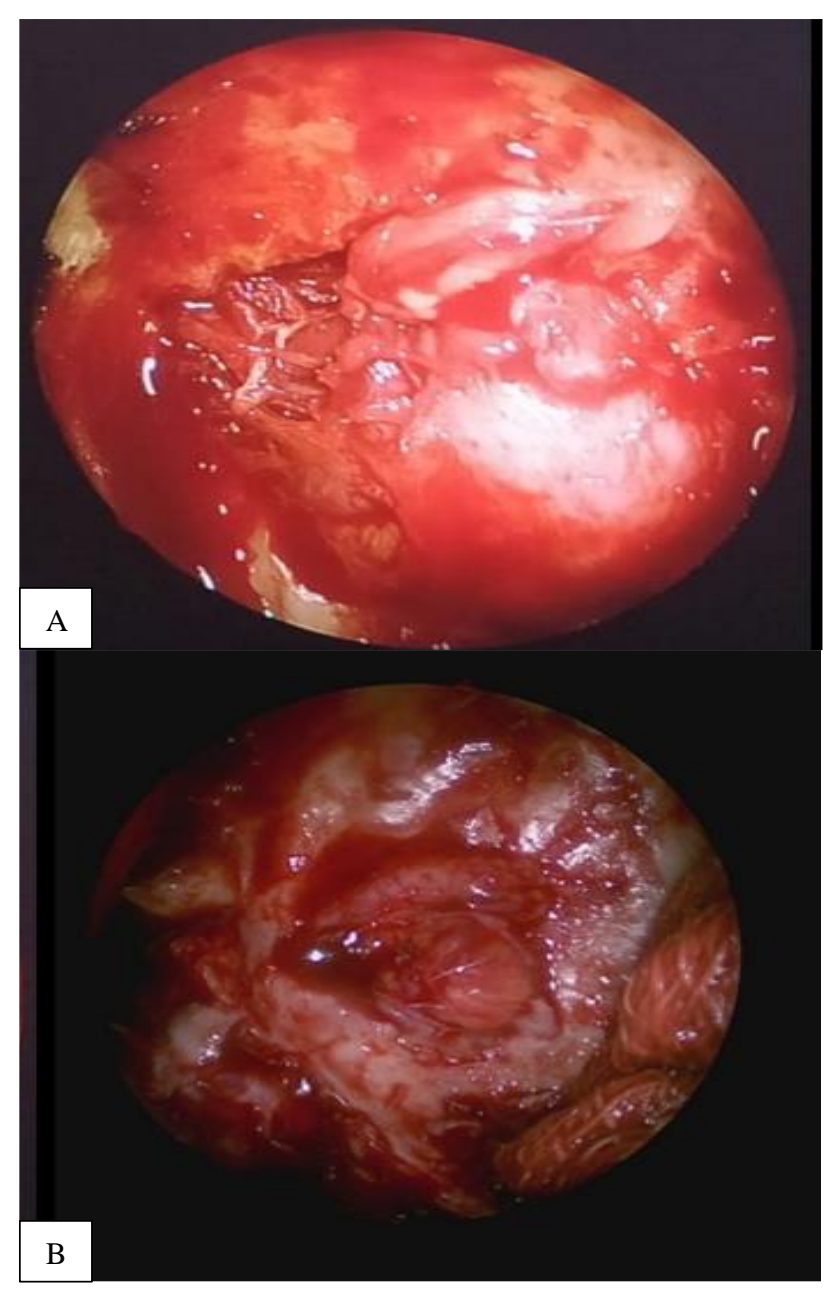

Figure 3 (A and B): The intra-operative images of PPF region.

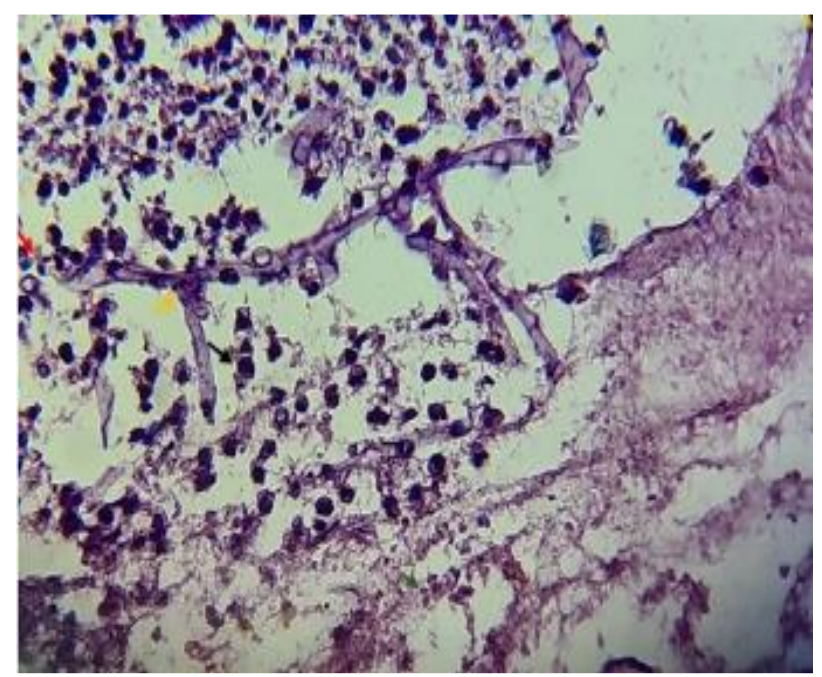

Figure 4: The histopathology of aseptate hyphae branching at obtuse angles in mucor (yellow arrow).

\section{Case 1}

A 55-year-old female came with chief complaints of nasal congestion, facial pain, and facial paresthesia for 6 days. She has a past history of COVID-19 infection 25 days ago, for which she was prescribed appropriate treatment. She was a known diabetic and hypertensive and was on irregular treatment. Her Hba1c was 13.1, serial general random blood sugar (GRBS) monitoring was done, and treatment was given accordingly. $\mathrm{KOH}$ mounts were negative for mucor, but liposomal amphotericin-B injection was started as medical treatment. In CT PNS, the fat stranding was noted involving retro maxillary zygomatic space of PPF area and extending laterally into the infratemporal fossa. Modified endoscopic Denker's approach of sinus surgery was performed.

\section{Case 2}

A 47-year-old male patient came with chief complaints of nasal obstruction, facial pain, facial paresthesia, loosening of teeth for 8 days. He has a past history of COVID-19 infection 61 days ago, for which he was hospitalized and was on oxygen therapy for 3 days also. Since then, he was diagnosed as a denovo diabetic and has been on regular treatment. He stopped using the treatment for diabetes after a month of COVID-19 infection. His Hbalc was 8.7, and urine analysis was positive for albumin and negative for sugar. Strict monitoring of GRBS was done, and treatment was given accordingly. $\mathrm{KOH}$ mounts were positive for mucor, and liposomal amphotericin-B injection was started. CT PNS showed the polypoidal mucosal thickening in the maxillary sinus; extensive erosions were noted involving all walls of the maxillary sinus with disease process extending into the PPF. The disease process was also seen extending inferiorly to gingival mucosa of upper canines, premolars, and molar teeth with permeative bony destruction of alveolar and palatine process of the maxilla. ESS with partial maxillectomy was performed.

\section{Case 3}

A 42-year-old female patient came with chief complaints of nasal congestion, facial pain, eye pain, proptosis, congestion of the eye for 6 days. She has a past history of COVID-19 infection, 42 days ago, for which she was prescribed appropriate treatment. She was a known diabetic and was on regular treatment. Her Hbalc was 8.9, serial GRBS monitoring was done, and treatment was given accordingly. $\mathrm{KOH}$ mounts were positive for mucor, and liposomal amphotericin-B injection was started. CT PNS showed soft tissue opacification with minimal fat stranding in the PPF extending laterally into the infratemporal fossa. Minimal inflammatory fat stranding was noted in intraconal and extraconal compartments of orbit. MRI orbits T2 fat-saturated hyperintensity was noted involving superior rectus and inferior rectus muscles with fat stranding in intraconal and extraconal compartments of orbit. Modified endoscopic Denker's approach of sinus surgery and orbitotomy with local debridement of the involved tissues was performed. 


\section{DISCUSSION}

Mucormycosis was first described by Paulltauf in $1885 .^{6}$ It is also known as zygomycosis and phycomycosis. They are ubiquitous fungi occurring in soil, air, skin, body orifices, manure, spoiled food, and dust. ${ }^{7}$ Once spores are inhaled with the nose, they proliferate in the sinuses and then to the orbit, subsequently to the brain. The primary mechanism of spread is through the angioinvasion of blood vessels. Following angioinvasion, mucormycosis causes injury through excessive vessel thrombosis and tissue necrosis. The angioinvasion also gives the fungus access to additional heme as a source of iron. ${ }^{8}$

Hyperglycemia in uncontrolled diabetes mellitus increases the risk of mucormycosis. It causes the glycosylation of iron sequestering proteins like transferrin, ferritin, and lactoferrin. Thereby, their affinity for iron is reduced, causing the proton-mediated displacement of ferric iron. ${ }^{9}$ This causes increased free iron levels even without acidosis. In hyperglycemia with ketoacidosis, the presence of ketone bodies like $\beta$ hydroxybutyrate [BHB] and low $\mathrm{pH}$ in the blood vessels effectively impairs the ability of transferrin to chelate iron. ${ }^{10}$ This increased available serum iron is transported intracellularly by the reductase-permease system. ${ }^{11,12}$ Glucose, iron, and BHB stimulate the expression of glucose regulated protein-78 (GRP-78) and Cot H. This enhanced expression results in the growth of the fungus and the augmented fungal invasion with subsequent injury of the endothelium. ${ }^{13,14}$ All these host factors suppress the $\mathrm{T}$ lymphocyte induction, IFN- $\gamma$ (interferon) production, and phagocyte-mediated killing. ${ }^{14}$ Ketoacidosis further impairs chemotaxis and phagocytosis of the neutrophils and facilitates the dissemination of the fungus. , $^{8,15,16}$

In our study, COVID-19 had a major role in the very first place. Diabetes mellitus strongly impacted COVID-19 in exaggerating this so-called black fungus. ${ }^{17}$ Early detection and multidisciplinary team approach play a definite role in saving the patients from this lifethreatening disease.

The 51 to 60 years aged patients were affected the highest, which might be because of the declining immunity levels in addition to COVID-19 and deranged blood sugar levels. Sen et al reported six cases of rhinoorbital mucormycosis with a mean age of 60.5 years. ${ }^{18}$

Radiological imaging like CT and MRI paranasal sinuses aided in the detection of areas like PPF. There was fat stranding with soft tissue thickening noted involving retro maxillary areas of PPF in CT PNS. On T1 and T2 fat sat imaging of MRI, there is soft tissue thickening with fat stranding in PPF. On post-contrast with gadopentetate, T1 imaging showed enhancement of this area. Shrestha et al reported $\mathrm{T} 2 \mathrm{~W}$ signal intensity is determined by extent of necrosis (causing hyper intensity), and on post contrast scans, the contents of the sinuses may show intense homogenous enhancement. ${ }^{19}$

Liposomal amphotericin-B was a great lifesaving drug and first-line therapy. ESS via modified Denker's approach was performed in about 21 patients, which showed good clearance of the disease process involving the PPF. Amphotericin-B is the first-line choice of therapy, further Posaconazole, isuvaconazole can also be prescribed. $^{20}$ Combined approach therapy is always helpful than monotherapy. Amphotericin B alone or surgical debridement alone doesn't help the patient and poses fatal outcomes. So surgical debridement plus medical treatment decreases the morbidity of the patients. The mortality rate of patients treated with amphotericin B alone was $50-61 \%$ compared to the combined therapy of surgical debridement and amphotericin B used, which accounted for about $19-44 \% .^{21}$

Brunet and Rammaert have recommended liposomal amphotericin B as the first-line therapy for the treatment of mucormycosis along with surgery whenever possible. ${ }^{22}$

Nithyananda et al in their study on the clinical features and treatment outcomes of mucormycosis, have reported that debridement of sinuses is necessary in all cases. ${ }^{23}$

Endoscopic nasal debridement and ESS were done for those cases which had the involvement of nose and para nasal sinuses. The debridement was done for mucosa and bone until a good vascular bed was visualized.

The modified endoscopic Denker's approach was performed for cases involving retro maxillary area, PPF, and infratemporal fossa area. This approach gave very good access to the anterior, posterior, and lateral walls of the maxilla and PPF and infratemporal fossa areas, which are the most inaccessible areas with the basic ESS.

Orbitotomy and surgical debridement of the local tissues like the fat, extraocular muscles was performed if the above-mentioned structures were involved.

The involvement of areas like the hard palate, alveolar process of maxilla extending up to the zygomatic arch region were worked upon by the transoral approach of maxillectomy. Sublabial maxillectomy or total maxillectomy was performed according to the involvement of the disease process.

Early diagnosis, aggressive surgical debridement, and antifungal drug therapy is the key to improving survival. Procedures such as endoscopic orbital clearance, sublabial maxillectomy, and Denker's approach may facilitate access and surgical debridement. Posaconazole has emerged as an effective alternate/adjunct antifungal drug in the management of these patients. ${ }^{24}$

Overall, our study revealed that 6 patients had a disease recurrence but not pertaining only to the PPF area, but 
extending to other sites like infratemporal fossa, hard palate and orbital regions. This might be due to the incomplete micro clearance of pathogen infected tissue resulting in aggressive spread of the disease. A total of 4 patients died due to other medical complications.

\section{CONCLUSION}

Rhino orbital mucormycosis is a fatal disease. Early detection of the disease, control of blood sugar levels, proper tapering of steroids could decrease the severity of the disease. Radiological imaging with CT and MRI was like a roadmap for the involvement and extent of the disease. Appropriate antifungals plus surgical debridement and multidisciplinary teamwork can lead to better lives for these patients.

\section{ACKNOWLEDGEMENTS}

Author would like to thank all our allied departments of otorhinolaryngology, ophthalmology, oral maxillofacial surgery, radiodiagnosis, microbiology and pathology. I thank Dr. Praveen Kumar Simhadri in guiding me throughout this project. I sincerely thank all our patients for their cooperation and coordination.

\section{Funding: No funding sources}

Conflict of interest: None declared

Ethical approval: Not required

\section{REFERENCES}

1. Skiada A, Pavleas I, Drogari-Apiranthitou M. Epidemiology and diagnosis of mucormycosis: an update. J Fungi. 2020;6(4):265.

2. Honavar SG. Code mucor: guidelines for the diagnosis, staging and management of rhino-orbitocerebral mucormycosis in the setting of COVID- 19. Indian J Ophthalmol. 2021;69(6):1361-5.

3. Revannavar SM, Supriya PS, Samaga L, Vineeth VK. COVID-19 triggering mucormycosis in a susceptible patient: a new phenomenon in the developing world? BMJ Case Rep CP. 2021;14(4):e241663.

4. Cappello ZJ, Potts KL. Anatomy, Pterygopalatine Fossa. Treasure Island (FL): Stat Pearls Publishing. 2022.

5. Ilahi S. Physiology, pineal gland. Stat Pearls Available at: https://www.ncbi.nlm.nih.gov/books/NBK525955/. Accessed on 29 April 2021.

6. Paltauf A. Mycosis Mucorina. Virchows Arch Pathol Anat Physiol Klin Med. 1885;102:543-64.

7. Naussbaum ES, Holl WA. Rhinocerebral mucormycosis: changing patterns of disease. Surg Neurol. 1994;41:152-6

8. Ibrahim AS, Spellberg B, Walsh TJ, Kontoyiannis DP. Pathogenesis of mucormycosis. Clin Infect Dis. 2012;54(1):S16-22.
9. Ribes JA, Vanover-Sams CL, Baker DJ. Zygomycetes in human disease. Clin Microbiol Rev. 2000;13(2):236-301.

10. Artis WM, Fountain JA, Delcher HK, Jones HE. A mechanism of susceptibility to mucormycosis in diabetic ketoacidosis: transferrin and iron availability. Diabetes. 1982;31(12):1109-14.

11. Baldin C, Ibrahim AS. Molecular mechanisms of mucormycosis-The bitter and the sweet. PLoS pathog. 2017;13(8):e1006408.

12. Liu M, Lin L, Gebremariam T, Luo G, Skory CD, French SW et al. Fob1 and Fob2 Proteins Are Virulence Determinants of Rhizopus oryzae via Facilitating Iron Uptake from Ferrioxamine. PLoS Pathog. 2015;11(5):e1004842.

13. Liu M, Spellberg B, Phan QT, Fu Y, Lee AS, et al. The endothelial cell receptor GRP78 is required for mucormycosis pathogenesis in diabetic mice. J Clin Invest. 2010;120(6):1914-24.

14. Gebremariam T, Lin L, Liu M, Kontoyiannis DP, French S, Edwards JE Jr et al. Bicarbonate correction of ketoacidosis alters host-pathogen interactions and alleviates mucormycosis. J Clin Invest. 2016;126(6):2280-94.

15. Binder U, Maurer E, Lass-Flörl C. Mucormycosisfrom the pathogens to the disease. Clin Microbiol Infect. 2014;20(6):60-6.

16. Ribes JA, Vanover-Sams CL, Baker DJ. Zygomycetes in human disease. Clin Microbiol Rev. 2000;13(2):236-301.

17. www.thelancet.com. 2021;398.

18. Sen M, Lahane S, Lahane TP, Parekh R, Honavar SG. Mucor in a viral land: A tale of two pathogens Indian J Ophthalmol. 2021;69:244-52.

19. Sreshta K, Dave TV, Varma DR, Nair AG, Bothra N, Naik $M N$ et al. Magnetic resonance imaging in rhino-orbital-cerebral mucormycosis. Indian $\mathbf{J}$ Ophthalmol. 2021;69(7):1915-27.

20. Cornely OA, Alastruey-Izquierdo A, Arenz D, Chen SCA, Dannaoui E, Hochhegger B et al. Global guideline for the diagnosis and management of mucormycosis: An initiative of the European Confederation of Medical Mycology in co-operation with the Mycoses Study Group Education and Research Consortium. Lancet Infect Dis. 2019;19:e405-21.

21. Jeong W, Keighley C, Wolfe R, Lee WL, Slavin MA, Chen SCA, Kong DCM. Contemporary management and clinical outcomes of mucormycosis: A systematic review and metaanalysis of case reports. Int $\mathbf{J}$ Antimicrob Agents. 2019;53:589-97.

22. Brunet K, Rammaert B. Mucormycosis treatment: Recommendations, latest advances, and perspectives. J Mycol Med. 2020;30:101007.

23. Nithyanandam S, Jacob MS, Battu RR, Thomas RK, Correa MA, D'Souza O. Rhino-orbito-cerebral mucormycosis. A retrospective analysis of clinical features and treatment outcomes. Indian $\mathbf{J}$ Ophthalmol. 2003;51:231-6. 
24. Vaid N, Mishra P, Gokhale N, Vaid S, Vaze V, Kothadiya $\mathrm{A}$ et al. A proposed grading system and experience of COVID-19 associated rhino orbito cerebral mucormycosis from an Indian Tertiary Care Center. Indian J Otolaryngol Head Neck Surg. 2021;1-8.
Cite this article as: Darla P, Siripalli JS, Deeganta M. Pterygopalatine fossa, a hive for fungus in rhino orbital mucormycosis-a case series. Int J

Otorhinolaryngol Head Neck Surg 2022;8:244-51. 